\title{
Grain structure of laser remelted 7075 aluminium alloy in presence of $\mathrm{Al}_{2} \mathrm{O}_{3}$ particles
}

\author{
K. Zhang and G. N. Chen
}

The effect of inert particles on grain structure development from alloy melt during laser rapid solidification has been investigated. It is found that the presence of $\mathrm{Al}_{2} \mathrm{O}_{3}$ particles may disrupt the usual epitaxial grain structure evolution of an aluminium 7075 alloy when processed by laser surface remelting. This result, in addition to observations of crystal termination at the particles and grain refinement in particle dense regions, indicates that a mechanism of particle restricted grain growth operates.

MST/4747

The authors are in the Materials Center, Institute of Mechanics, Chinese Academy of Sciences, 15 Zhongguancun Road, Beijing 100080, China (kzhang@imech.ac.cn). Manuscript received 28 June 2000; accepted 11 September 2000.

(C) 2001 IoM Communications Ltd.

\section{Introduction}

Grain structure is one of the important features influencing the mechanical and/or physical properties of metallic materials. For the situation of surface remelting or welding involving rapid solidification, a resolidified zone is usually characterised by an epitaxial columnar grain structure, except for occasional observations of other grain structures such as stray grains and equiaxed grains in pool centrelines.

Under specific conditions, however, a fully non-epitaxia grain structure may be obtained in remelted zones. Earlier work by Kou and $\mathrm{Le}^{1}$ showed that high-frequency arc oscillation produced notable grain refinement in welds of 5052 aluminium alloy (based on $\mathrm{Al}-0.25 \mathrm{Si}-0.40 \mathrm{Fe}-$ $2 \cdot 5 \mathrm{Mg}-0 \cdot 25 \mathrm{Cr}$, wt- $\%$ ). Rieker and Morris ${ }^{2}$ observed an equiaxed microcrystalline structure in laser alloyed ferritic stainless steel, as compared to an epitaxial columnar grain structure in laser alloyed austenitic stainless steel. Gremaud et al. $^{3}$ revealed that, at high laser scanning rates, a transition from constrained growth to nucleation control of microstructure evolution occurred in laser remelted $\mathrm{Al}-\mathrm{Si}$ alloy. Although some arguments have been put forward to elucidate grain structure development, the mechanisms remain unclear due to complexities of nucleation phenomena, ${ }^{3}$ and for that much more work is required.

This paper investigates experimentally the effect of $\mathrm{Al}_{2} \mathrm{O}_{3}$ particles on grain structure development during laser remelting of 7075 aluminium alloy. As well as pursuing insight into the grain selection mechanism, there are implications for control of microstructure of particle reinforced metal matrix composites (PMMC), when processed by various solidification processes such as surface remelting or welding of PMMC parts, or alloying or cladding of surface PMMC on metallic parts. ${ }^{4-7}$ Indeed, related information on this topic is rather limited. ${ }^{4}$

\section{Experimental}

The parent materials were 7075 aluminium alloy (of nominal composition $\mathrm{Al}-0.40 \mathrm{Si}-0.50 \mathrm{Fe}-(\sim 1.6) \mathrm{Cu}-$ $0 \cdot 3 \mathrm{Mn}-(\sim 2 \cdot 5) \mathrm{Mg}-(\sim 0.23) \mathrm{Cr}-(\sim 5 \cdot 6) \mathrm{Zn}-0.2 \mathrm{Ti}, \quad$ wt- $\%)$ containing 0 and 10 vol. $-\% \mathrm{Al}_{2} \mathrm{O}_{3 p}(6 \mu \mathrm{m}$ in diameter $)$, respectively. They were prepared by a permanent mould casting process and subsequently $\mathrm{T} 4$ heat treated. Typical grain size values of 50 and $52 \mu \mathrm{m}$ were obtained for the monolithic alloy and reinforced alloy, respectively.

The laser remelting experiments were carried out using a continuous wave $1.5 \mathrm{~kW} \mathrm{CO}$ laser. The diameter of laser beam $d$ was set at $2 \mathrm{~mm}$, beam power $P$ was $600 \mathrm{~W}$, and the scanning velocity $V$ was $30 \mathrm{~mm} \mathrm{~s}^{-1}$. A preliminary study demonstrated that, under such conditions, particle melting and particle-matrix reaction can be avoided. Optical microscopic observations of longitudinal sections taken through the centre of the laser traces were made. An appropriate etching solution was used to etch metallographic specimens. By adjusting the etching conditions such as time and temperature, grain structure and subgrain structure could be revealed separately.

\section{Results and discussion}

The resolidified matrix microstructures of the two materials were hypoeutectic, as shown in Fig. $1 a$ and $b$. This indicates that the solidification mode remained primary $\alpha-\mathrm{Al}$, irrespective of the addition of particles. However, the presence of particles was found to disrupt the orderly aligned arrangement of $\alpha$-Al observed in the monolithic alloy. A similar observation has been made on laser clad $\mathrm{SiC}_{\mathrm{p}} / \mathrm{Ti}$ composites. ${ }^{5}$ In addition, there is evidence of primary dendrites terminating at a particle, as shown in Fig. $1 b$.

It is well known that $\mathrm{Al}_{2} \mathrm{O}_{3}$ does not act as a heterogeneous nucleation site for $\alpha-\mathrm{Al}^{8}{ }^{8}$ In such a case, according to Rohatgi et al. ${ }^{9}$ and Liu et al. ${ }^{10}$ distortion of subgrain structure might be responsible for the chaotic growth of the primary solidifying phase. They believed that, since the ceramic particles act as barriers to solute and heat transfer, disturbed solute fields and temperature fields may thus give rise to unsteady solidification. Once an unsteady branched dendritic structure is formed, one may detect irregular growth in any given columnar grain. If so, disturbed solute fields should play a major role in determining the growth behaviour, due to the fact that crystal growth in alloy melts is primarily influenced by solute diffusion rather than by thermal conductivity.

The grain structure in laser processed zones, as shown in Fig. 2, identified the contribution to disorder growth to be mainly from a change in the grain structure. For the laser treated alloy with particles present, a fully non-epitaxial columnar structure characterised by the continual appearance of new grains in the laser scanning direction is obtained. Sometimes, equiaxed grains are observed in the bottom of the fusion zone (Fig. $2 b$ ). This morphology differs significantly from the usual epitaxial grain structure obtained in the bulk alloy (Fig. $2 a$ ).

According to Hunt's model, ${ }^{11}$ nucleation ahead of the advancing interface in directional solidification is encour- 


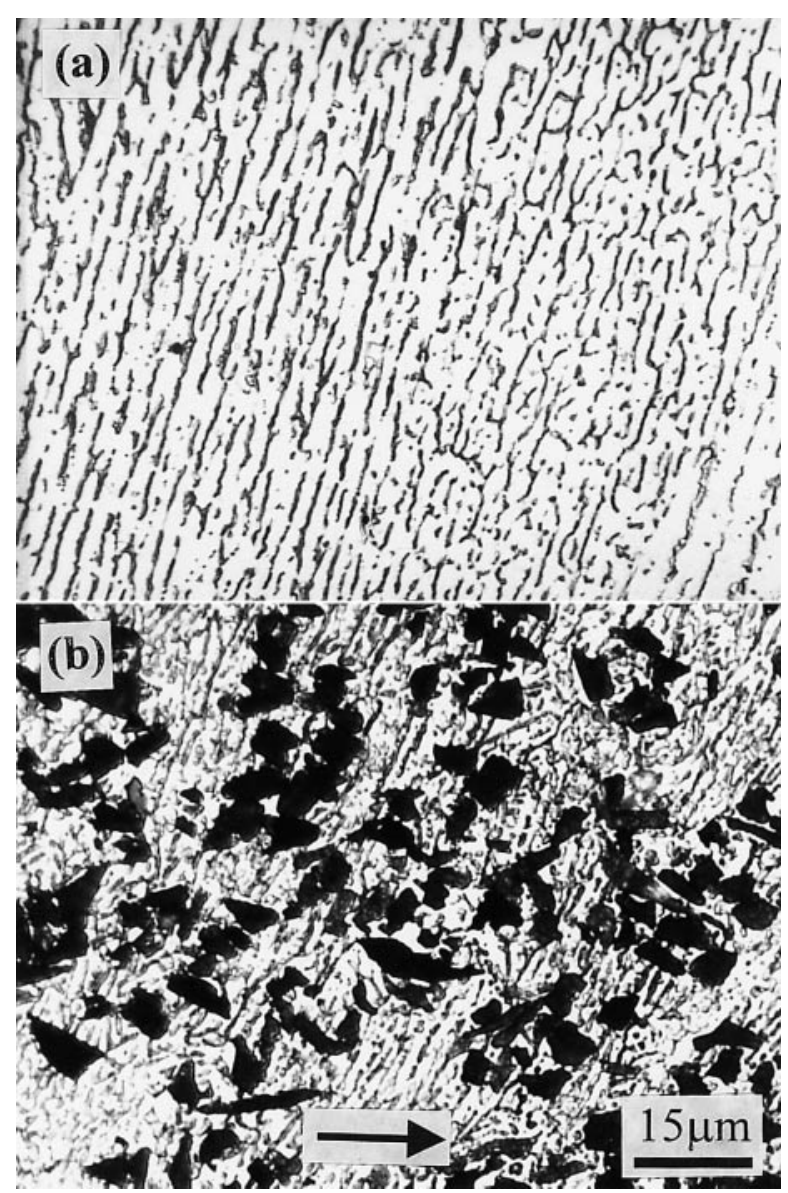

a 7075 alloy; $b 7075-10 \% \mathrm{Al}_{2} \mathrm{O}_{3 p}(6 \mu \mathrm{m})$

1 Subgrain structures of laser remelted alloys under similar processing conditions: arrow indicates direction of beam travel

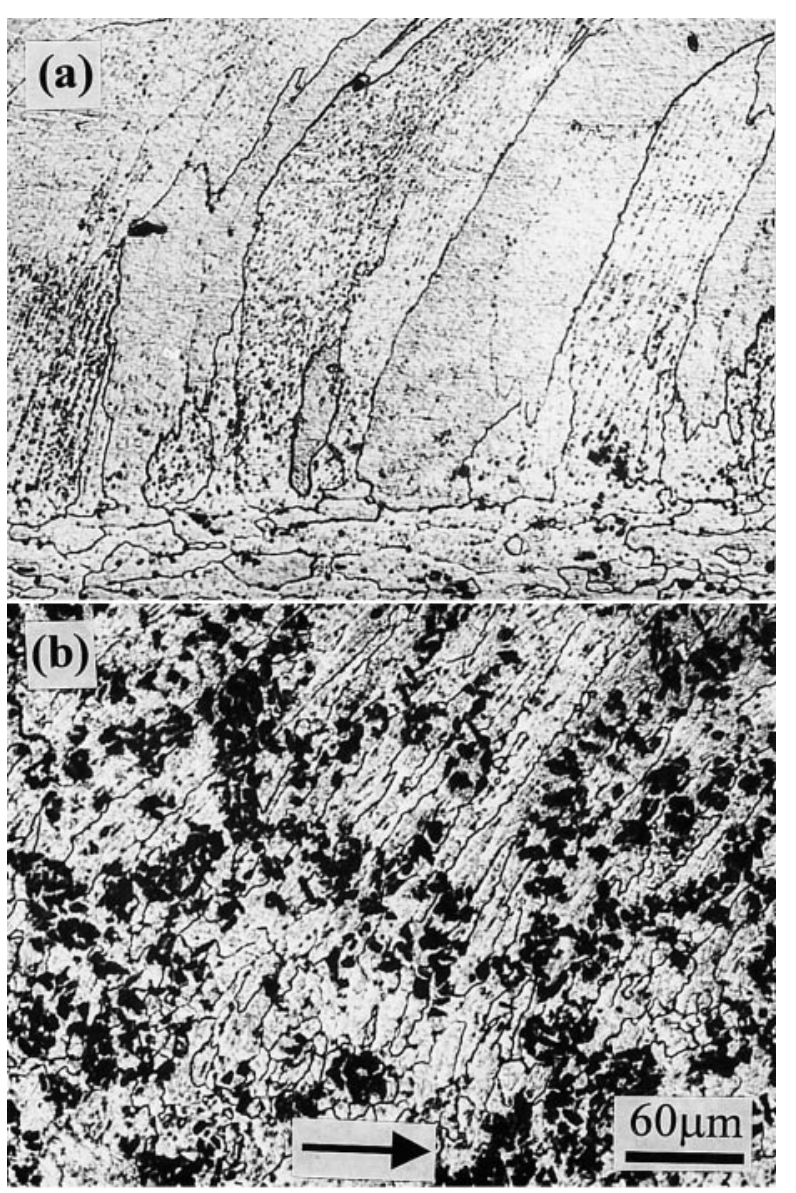

a 7075 alloy; $b 7075-10 \% \mathrm{Al}_{2} \mathrm{O}_{3 \mathrm{p}}(6 \mu \mathrm{m})$

2 Grain structures of laser remelted alloys under identical processing conditions: arrow indicates direction of beam travel aged by a low thermal gradient. This is the case for the formation of stray grains or equiaxed grain structures near the weld centreline during conventional welding. In particular, if the thermal gradient in the whole remelted zone is lowered by using a magnetic arc oscillation technique, a fully non-epitaxial grain structure can be obtained. ${ }^{1}$ In this work, the addition of particles results in an increase in thermal gradient in the pool due to the lower thermal conductivity of the particles compared with the alloy melt. Hence, although any role of low thermal gradient on grain structure transition can be ruled out, instead a mechanism based on particle restricted grain growth, as follows, may be applicable.

It is theoretically postulated that, depending on solidification front velocity and particle size, particles may or may not be pushed by the advancing solidification interface $^{12}$ After remelting, the distribution of particles was found to remain very close to the original in this work. This implies that, at high solidification rates, no particle pushing was favoured. At the same time, particles cannot be engulfed (or entrapped) by any given dendrite, because dendrite tip diameter (or dendrite spacing) is smaller than dispersoid size (Fig. 1b). Therefore, dendrites that encounter particles will stop growing, whereas other dendrites continue to grow through the interstices between particles. The interstices diverge and converge so that new secondary and tertiary arms develop to fill the open space of the liquid. The undercooling at the tip of new secondary arms is larger than that of the primary dendrite tips, ${ }^{13}$ so new crystals are thus expected to nucleate and grow to visible size. Obviously, if the particles are pushed by the solidification interface as a result of a low solidification rate, they cannot restrict grain growth and an epitaxial grain structure still develops. ${ }^{4}$

In fact, nucleation phenomena in the open space of liquid has been demonstrated to be present in directionally solidified ingots with shape variation, i.e. divergence in their cross-sections. ${ }^{14,15}$ Especially, this phenomenon has been observed in situ during directional solidification of transparent succinonitrile-acetone. ${ }^{16}$ According to the model of Gandin et al. ${ }^{13}$ the probability of nucleating a new crystal is increased in larger open spaces with increase in cooling rate. For alloy melt containing the particles, the width of open spaces is of the order of the particle radius, which is much smaller than that in Refs. 14 and 15 . Nevertheless, it is expected that the mechanism of particle restricted growth may still operate because of the rather high cooling rate in this work.

The above mechanism is further demonstrated by the effect of particle distribution on grain size in the resolidified pool. As can be seen in Fig. $3 a$ and $b$, the grain size in regions of high particle density is finer than in sparse regions of the same specimen. Higher particle content provides a better chance for the melt to generate more new nuclei and hence, leads to a relative refinement of grain structure.

The mechanism for the loss of epitaxial relationship with the unmelted substrate in this work is different from that in Refs. 2 and 3, where a large interfacial undercooling and a number of efficient nucleants were expected to have been present. Indeed, the nucleation rate is believed not to be high in this work. As a result, many of the grains grow a considerable distance in the direction of the positive thermal 


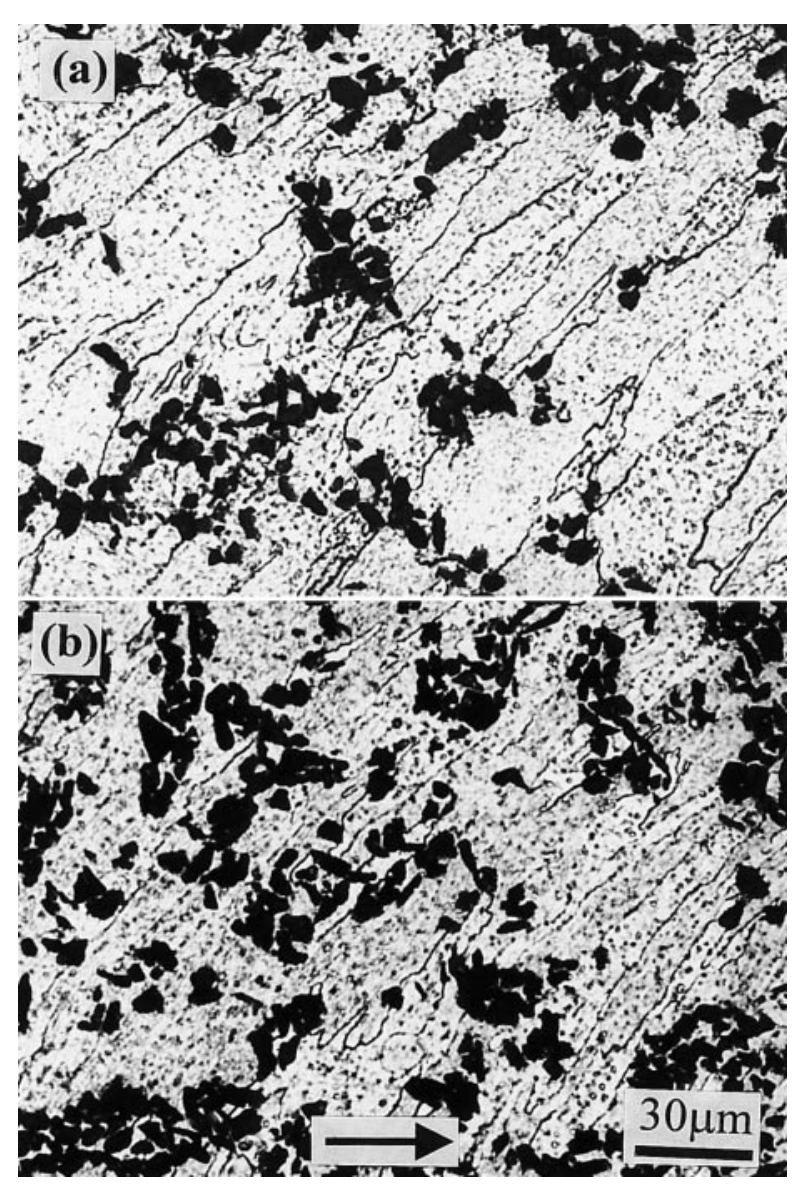

3 Grain size after laser remelting in a particle sparse region; $b$ particle rich region

gradient, and appear elongated in morphology, as seen in Fig. $2 b$. In contrast, a fully equiaxed grain structure was found in Refs. 2 and 3.

\section{Conclusions}

Summarising the grain evolution phenomena during laser remelting of an aluminum 7075 alloy, it can be concluded that the presence of $\mathrm{Al}_{2} \mathrm{O}_{3}$ particles can restrict the crystal growth of primary $\alpha$-Al. A higher particle volume fraction and larger particle size promote the transition from fully columnar regrowth to fully non-epitaxial grain structure development in the laser remelted zone.

\section{Acknowledgements}

This work was supported by the National Natural Science Foundation of China (Grant no. 59836220).

\section{References}

1. S. KOU and Y. LE: Metall. Trans. A, 1985, A16, 1345-1352.

2. C. RIEKER and D. G. MORRIS: Mater. Sci. Eng. A, 1991, A133, $854-858$.

3. M. GREMAUD, D. R. ALLEN, M. RAPPAZ, and J. H. PEREPEZKO: Acta Mater., 1996, 44, 2669-2681.

4. H. W. DE VRIES and G. DEN OUDEN: Mater. Sci. Technol., 1999, 15, 202-206.

5. S. MRIDHA and T. N. BAKER: J. Mater. Process. Technol., 1997, 63, $432-437$.

6. K. P. COOPER, P. L. SLEBODNICK, K. E. LUCAS, and E. A. HOGAN: $J$. Mater. Sci., 1998, 33, 3805-3816.

7. Y. B. LIU, J. D. HU, Z. Y. CAO, and P. K. ROHATGI: Wear, 1997, 206, $83-86$.

8. A. MORTENSEN and I. JIN: Int. Mater. Rev., 1992, 37, (3), 101128.

9. P. K. ROHATGI, K. PASCIAK, C. S. NARENDRANATH, S. RAY, and A. SACHDEV: J. Mater. Sci., 1994, 29, 5357-5366.

10. Y. H. LIU, Z. M. HE, S. F. LIU, and Z. C. YANG: J. Mater. Sci. Lett., 1993, 12, 254-256.

11. J. D. HUNT: Mater. Sci. Eng., 1984, 65, 75-83.

12. R. J. ASthana: J. Mater. Sci., 1998, 33, 1679-1698.

13. A. DE BUSSAC and CH. A. GANDIN: Mater. Sci. Eng. A, 1997, A237, 35-42.

14. J. LAPIN and J. IVAN: Scr. Metall., 1995, 33, (5), 391-397.

15. M. RAPPAZ, CH.-A. GANDIN, J.-L. DESBIOLLES, and PH. THEVOZ: Metall. Trans. A, 1996, A27, 695-670.

16. L. M. FABIETTI, V. SEETHARAMAN, and R. TRIVEDI: Metall. Trans. $A, 1990, \mathbf{A 2 1}, 1299-1310$ 